\title{
Visualization of Combustion and CFD Study for NOx Reduction with Water Injection *
}

\author{
ByTakasaki, Koji **, Tajima, Hiroshi**, Strøm, Alexander** and Murakami, Shinsuke**
}

\begin{abstract}
The Shipbuilding Research Association of Japan started a project in 2003 to develop a direct water injection (DWI) system to decrease NOx formation through the reduction of flame temperatures at the combustion stage in marine diesel engines. In this project, it was decided that an $80 \%$ reduction in NOx emission must be achieved with a less than $3 \%$ increase in specific fuel consumption. To evaluate this system, high-speed photography of combustion was carried out using a visual test engine that had the same construction as a low-speed marine engine. Flame temperature decreases were visualized using the two-color method of digital photo data analysis. CFD calculations using KIVA code and StarCD were also made, and the behavior of sprays/flames and the temperature distribution in flames were successfully simulated. Furthermore, experiments to optimize the water injection system design, ensuring NOx reduction, were carried out using a constant volume combustion chamber simulating the engine running conditions.
\end{abstract}

\section{Introduction}

NOx regulations for marine engines (MARPOL 73/78 Annex VI) officially started last May. According to these rules, newly built engines running at speeds lower than 130 rpm must keep NOx emissions under $17 \mathrm{~g} / \mathrm{kWh}$. It was also decided that the allowable NOx value should be lowered every five years. In order to comply with these tightening regulations, new measures to reduce NOx emission must be developed urgently. The Shipbuilding Research Association of Japan started a project in 2003 to develop a direct water injection (DWI) system to decrease NOx formation at the combustion stage in marine diesel engines. This project involves many members from Japanese marine industries. Fig.1 shows the new NOx regulations. As shown in this figure, the second phase of regulation has already been planned, and a voluntary reduction to $3.5 \mathrm{~g} / \mathrm{kWh}$ ( $80 \%$ less than the above-mentioned $17 \mathrm{~g} / \mathrm{kWh}$ ) has been proposed in some countries. Considering these circumstances, the target of the Shipbuilding Research Association project was set to clear the voluntary value of $80 \%$ below the present level. At the same time, this project also aimed to minimize the sacrifice of specific fuel consumption (SFC) to carry out this NOx reduction. Thus, it was decided that the $80 \%$ reduction in NOx emissions must be achieved with a less than 3\%

\footnotetext{
* Received on April 6, 2006

** Interdisciplinary Graduate School of Engineering Sciences, Kyushu University,
}

increase in SFC.

The reason that DWI into the combustion chamber was selected for investigation in this project is as follows. It is considered that NOx emissions have their most harmful influence on the land when a ship is running near the coast or is in the harbour. Thus, the measure used for NOx reduction must be effective at low load operations. At such low loads, however, exhaust gas after-treatment using catalysts like SCR will not work well because the exhaust gas temperature is too low for the catalytic reaction. Fortunately, adding water into the combustion chamber is effective in limiting NOx formation throughout the load range, as water or steam injected into the flame always decreases combustion temperatures owing to its high specific heat.

A HAM (Humid Air Motor: Humidification of intake air) system was not proposed in this project. Although this type of system has the merit not requiring modification of the combustion chamber, a huge amount of water would be necessary to carry out an $80 \%$ reduction of $\mathrm{NOx}$ formation, as only about a half of the added water affects the flame at the combustion stage. Other than the HAM method, the following methods can also be used to inject water into the combustion chamber.

1. Fuel-water emulsion

2. Stratified fuel water injection

3. Direct water injection (DWI) with a "two-needle type" 
fuel and water injection nozzle

4. DWI with a "separate water injection nozzle"

The authors of this paper have closely examined all of the above-mentioned fuel + water injection systems for medium and large sized diesel engines. Accordingly, it was estimated that almost the same volume of water as fuel should be injected to carry out an $80 \%$ NOx reduction with any of these systems. Considering the required volume of water, the fuel-water emulsion and the stratified fuel water injection,

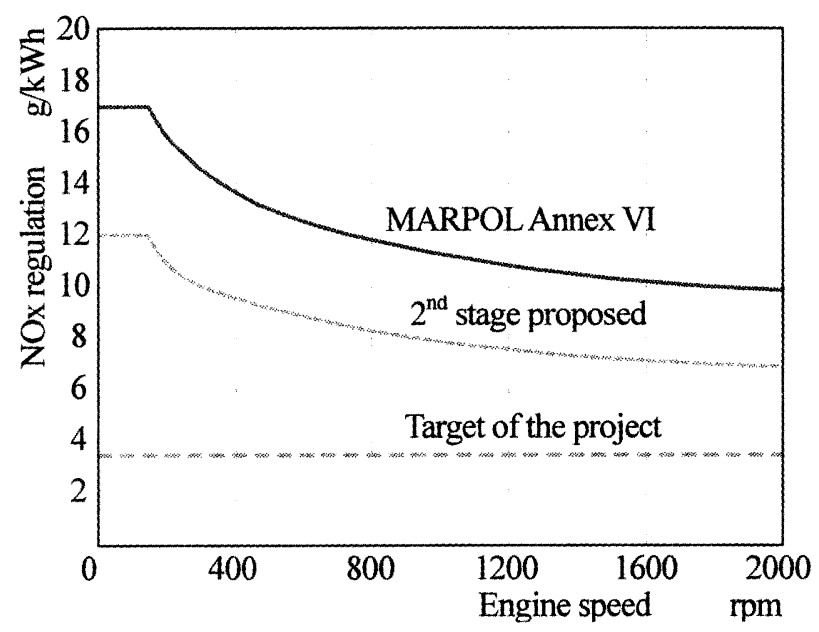

Fig.1 Target of the project for which fuel and water are injected through the same injection nozzle hole, would be difficult to implement since they would require a much larger injection system to inject double the amount of the liquid.

For the current project, the authors chose to investigate DWI. The main advantage of the DWI method is that water injection timing can be controlled independently of fuel injection. The authors of this paper have already reported some research on the "two-needle type" injection nozzle [1]. Thus, in the current investigation, visual and CFD studies of a DWI system with a "separate water injection nozzle" was examined.

The plan for this project is as follows. This paper describes parts 1 and 2 of this plan.

1. Development of CFD (Computed Fluid Dynamics) simulations to discuss the optimum water injection conditions.

2. Comparison of the CFD results and experimental data from a visual test engine and a constant volume combustion chamber (CVCC) to confirm the validity of CFD.

3. Running test using a single-cylinder 2-stroke test engine (Bore $400 \mathrm{~mm}$ ) equipped with a DWI system.

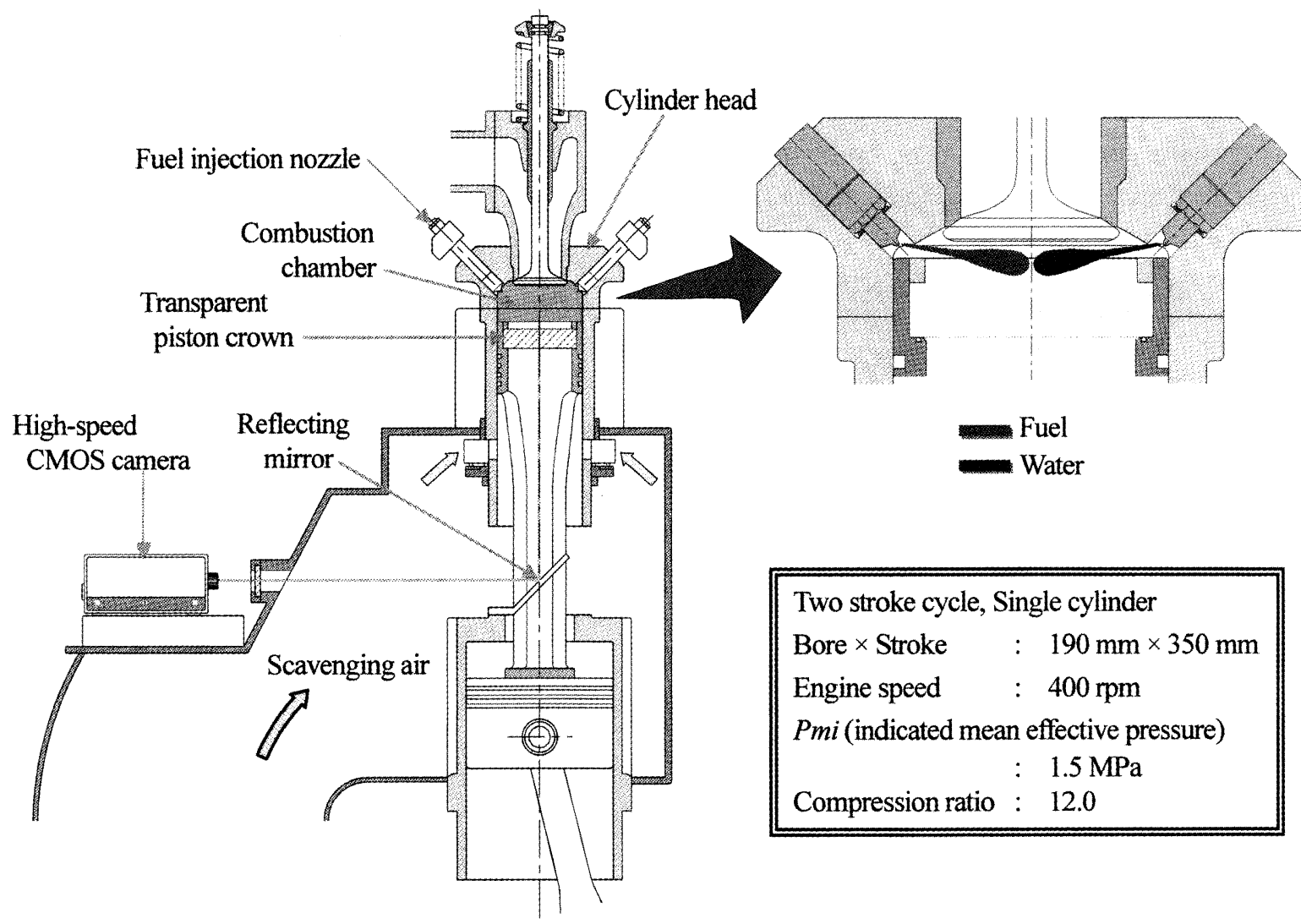

Fig.2 Schematics of visual test engine and its combustion chamber layout 


\section{Experimental Apparatus}

\subsection{Visual Test Engine}

To observe the combustion process, a single cylinder, uni-flow type 2-stroke cycle test engine with a $190 \mathrm{~mm}$ bore and a $350 \mathrm{~mm}$ stroke was used. This engine was equipped with a transparent piston as illustrated in Fig.2. The fuel used throughout all the experiments was marine diesel oil (MDO) available on the market. The test engine was externally super-charged to $0.28 \mathrm{MPa}$ scavenging air pressure. At the beginning of the experiment, the engine was driven by an electric motor to keep the glass window of the piston clear. After reaching a speed of $360 \mathrm{rpm}$, fuel was injected for 6 cycles $(1 \mathrm{sec})$ and the flame was photographed by a high-speed video camera. Fuel injection pressure was about $110 \mathrm{MPa}$. Measured air swirl velocity at the combustion stage was about $12 \mathrm{~m} / \mathrm{s}$.

A normal 2-stroke marine diesel engine with a 'side injection system' has at least two fuel injection nozzles (opposite to each other) per one cylinder. Likewise, in the visual test engine two fuel nozzles can be installed and a Pmi of $1.5 \mathrm{MPa}$ is possible when burning the fuel injected from two nozzles. However, when the photos used in this study were taken, only one nozzle was set, so as to observe one flame clearly, avoiding the overlapping of multiple flames. Therefore the quantity of fuel injected was half of what would be injected by two fuel injection nozzles.

The indicated thermal efficiency was measured by analyzing the indicator diagram of the firing cycle, obtained at the same time as the photography was carried out. However, NOx emissions could not be measured because the 6 firing cycles were too rapid for any kind of NOx measurement.

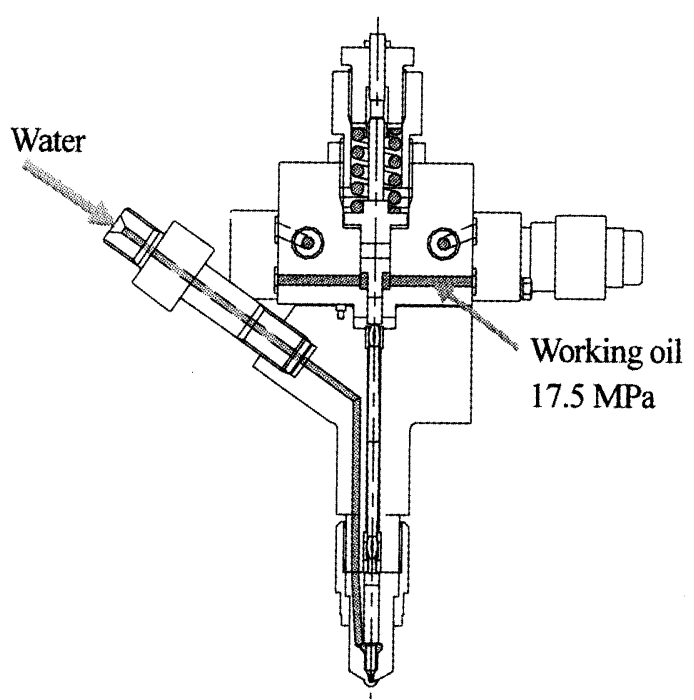

Fig.3 Schematics of water injection nozzle

\subsection{Water injection system}

A high-pressure water injection system was prepared for the test. Water was kept at a maximum pressure of $30 \mathrm{MPa}$ and injected into the combustion chamber using the water injection nozzle shown in Fig.3. At the time of injection, the nozzle needle seen in Fig.3 was opened by the working-oil pressure, controlled electronically, and was closed by the spring force discharging the oil pressure. Thanks to this system, water was injected at a constant injection pressure, ending sharply without lingering leaking.

In this project, three patterns of the water injection, shown in Fig.4, were tested using the visual test engine. In all the cases, the water injection holes were larger in diameter than the fuel injection holes, so as to keep the momentum of the water spray as high as that of the fuel spray, even though the water injection pressure was much lower than the fuel injection pressure. Water injection timing preceded and overlapped fuel injection in all cases, but its detail cannot be open here because of a patent-relating issue.

\subsection{Constant volume combustion chamber (CVCC)}

As it was impossible to measure NOx emissions from the visual test engine, a constant volume combustion chamber (CVCC), shown in Fig.5, modeling the combustion chamber of a long stroke engine, like the one that will be used in part 3 of this project, was used to obtain the NOx reduction data for the DWI system. Air swirl was generated with a rotating vane as seen in the figure. The measured swirl velocities were $10-12 \mathrm{~m} / \mathrm{s}$, almost same as in the visual test engine.

A fuel injection nozzle and a water injection nozzle were installed on the cover of the CVCC as seen in the figure. Fuel was injected by an electronically controlled, hydraulicactuated fuel injection system. The water injection system was the same as the one used in the visual test engine.

The test procedure was as follows. Fuel and water were
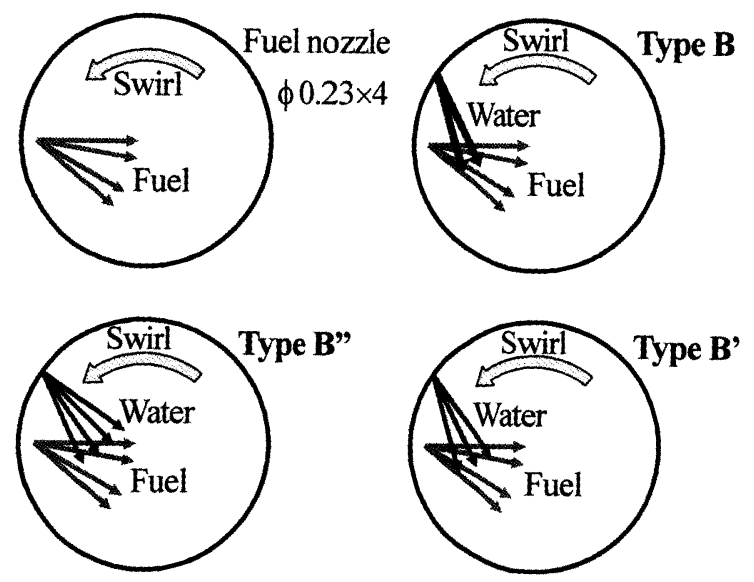

Fig.4 Water injection patterns in visual engine test 
injected into the chamber, which contained air at a pressure of $6 \mathrm{MPa}$ and a temperature of $850 \mathrm{~K}$. The same MDO (Marine diesel oil) as used in the visual test engine was injected for $12 \mathrm{~ms}$ with an injection pressure of $65 \mathrm{MPa}$. Such experimental conditions were equivalent to the half load of the single cylinder engine, which will be used in the running test in part 3 of this project.

After the self-ignition and combustion of the fuel, all of the exhaust gas was discharged from CVCC to a sampling bag. During this process, the sampled gas was mixed well, becoming homogeneous in the bag. Subsequently, the gas was transferred from the bag to a NOx analyser. In addition to NOx levels, the oxygen percentage was measured and NOx data was converted to the state of $13 \%$ oxygen.

CVCC test had the following advantages:

1. The influence of engine speed and fuel injection timing on NOx formation was fully eliminated.

2. It was possible to eliminate the influence of humidity on NOx formation by charging the chamber with dry air.

\section{Analysis and CFD Procedures}

\subsection{Two-Colour Method}

To obtain the flame temperature distribution from the visual test engine using the images taken by the high-speed video
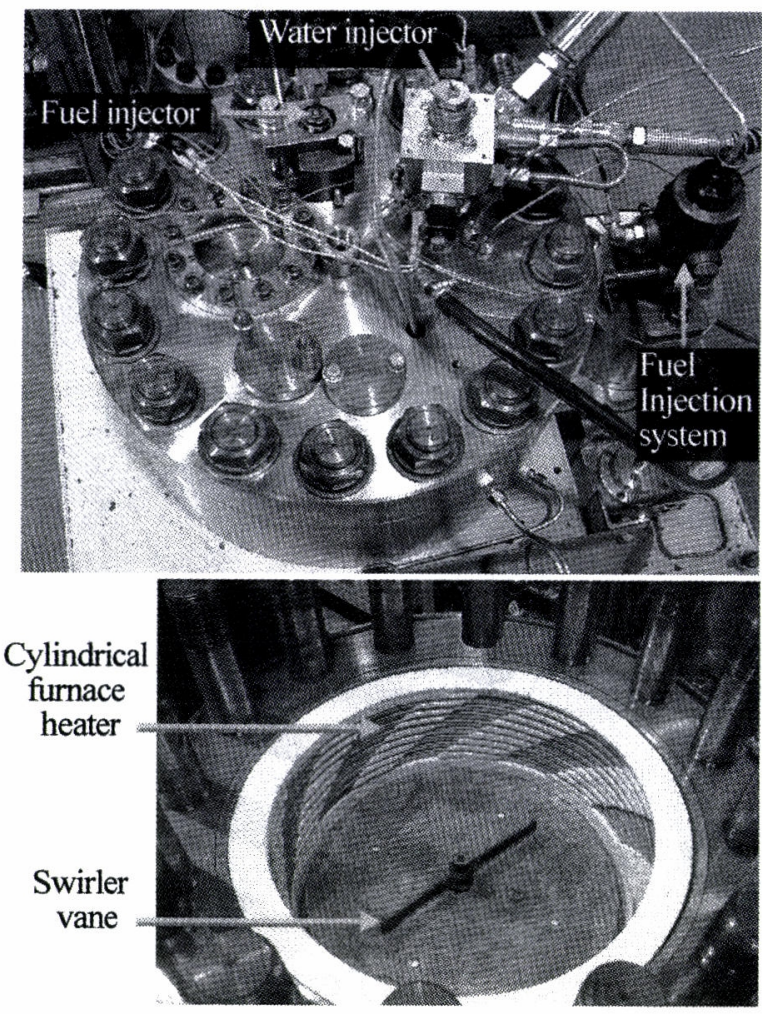

(CMOS) camera, the "two-colour method" explained in detail in the reference [1] was applied. Attention should be paid to ensure that the temperature analysed by this method represented the mean value through the flame thickness.

\subsection{Numerical CFD Simulations}

KIVA III and StarCD, well-acknowledged codes in the engine simulation field, were used to examine the effect of DWI on NOx formation. Both were used in a standard configuration except for some slight modification to handle the direct water injection [1]. To detect the distribution of injected water, StarCD code was more convenient than KIVA III. Computational grids used in the KIVA III were 19800 cells and for the StarCD simulations a radial mesh with further refinement in the region of combustion and NO formation was used, resulting in a grid of some 72000 cells. Calculation results on both codes were in good agreement in flame (temperature) distribution and tendency of NOx formation except for the NOx level, which was slightly higher in StarCD results because of its finer mesh size.

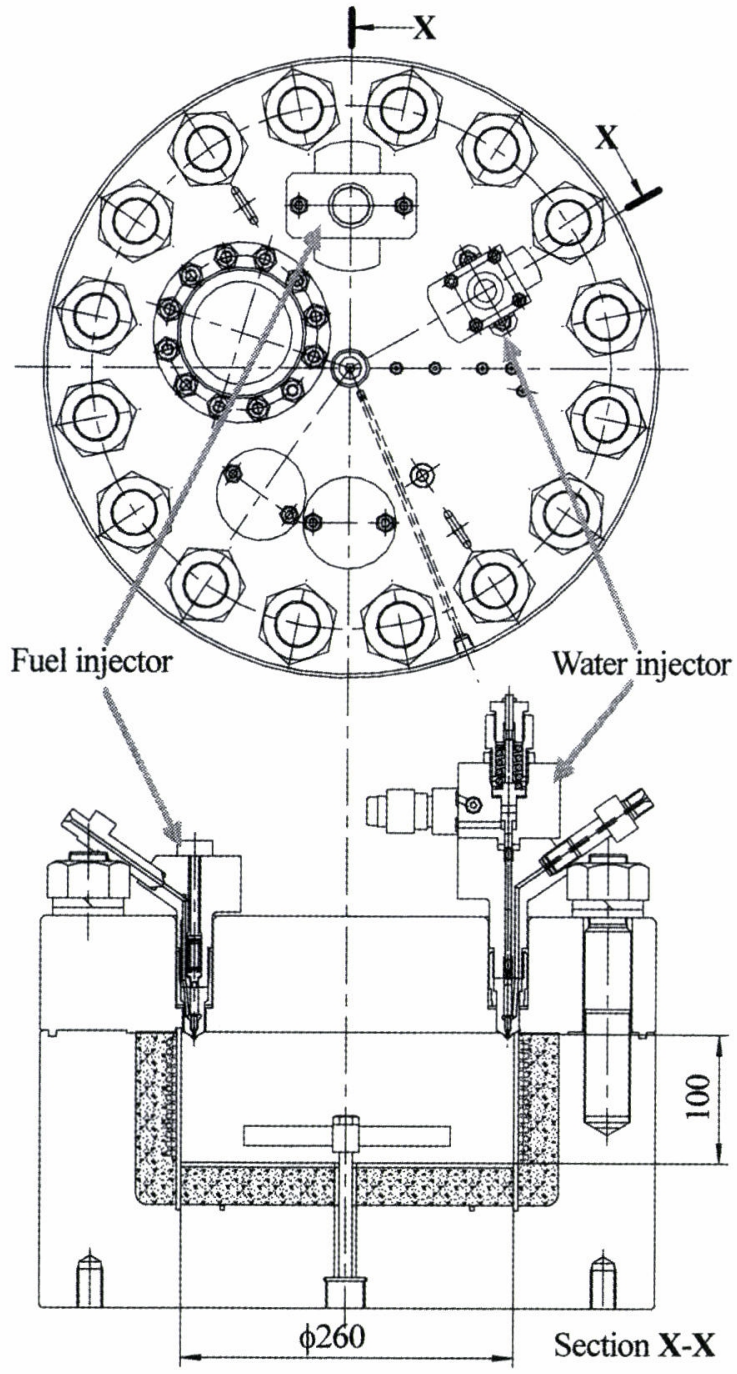

Fig.5 Schematics of CVCC 


\section{Results and Discussions}

\subsection{Experimental visual data and CFD results}

According to the established Zeldovich theory for NOx formation, if the flame combustion temperature is decreased, for example from $2400 \mathrm{~K}$ to $2200 \mathrm{~K}$ ( $-200 \mathrm{~K})$, the amount of NOx formed will be reduced to less than $20 \%$.

Fig.6 shows the comparison of experimental data from the visual test engine and the CFD illustrations derived from KIVA code simulating a combustion state with the same conditions as the visual test engine; this figure shows the case where no water is injected. The upper row (a) shows the experimental data, temperature distribution of the flame, analysed by the two-colour method. The data at 12,17 and $22 \mathrm{deg}$. ATDC are demonstrated. As the fuel injection duration is from $4 \mathrm{deg}$. BTDC to $18 \mathrm{deg}$. ATDC, the figures at 12 and $17 \mathrm{deg}$. ATDC represent the flame during the fuel injection, and the after-burning flame can be seen at $22 \mathrm{deg}$. ATDC.

CFD results, predicted flame temperature distributions and
NO concentrations $\left(\mathrm{g} / \mathrm{m}^{3}\right)$ at the horizontal plane $5 \mathrm{~mm}$ below the cylinder head are illustrated in (b) and (c). Exactly speaking, they cannot be directly compared with the experimental data in (a) that represents the mean temperature through the thickness of the flame as explained in 3.1.

As seen in the measured temperatures presented in (a), almost all of the area of the flame at the three time points is coloured red, indicating temperature in the range of 2250-2400 K. These data agree with the predicted temperature distributions shown in (b), which also have large areas in the range of 2300-2400 K. Furthermore, according to the calculated $\mathrm{NO}$ concentrations, illustrated in (c), there are spots where NO is actively formed in the hot areas of the flame, even at the after-burning stage at $22 \mathrm{deg}$. ATDC.

An example of the result of applying the type B" fuel injector is shown in Fig.7. As in Fig.6, the measured temperature distributions at three time points are shown in (a), the predicted temperature distributions are illustrated in

Fuel injection duration

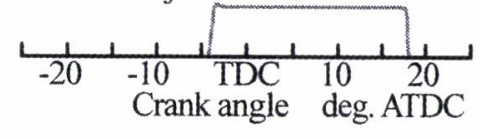

\section{Case: Fuel only}

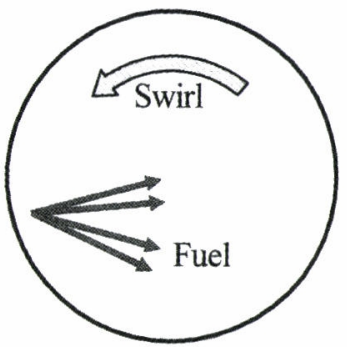

Fuel nozzle: $\phi 0.23 \times 4$

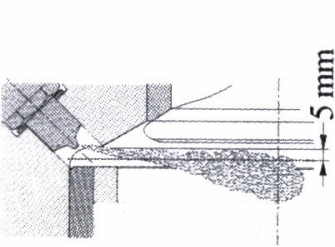

Calculated data are from a $5 \mathrm{~mm}$ cross-section
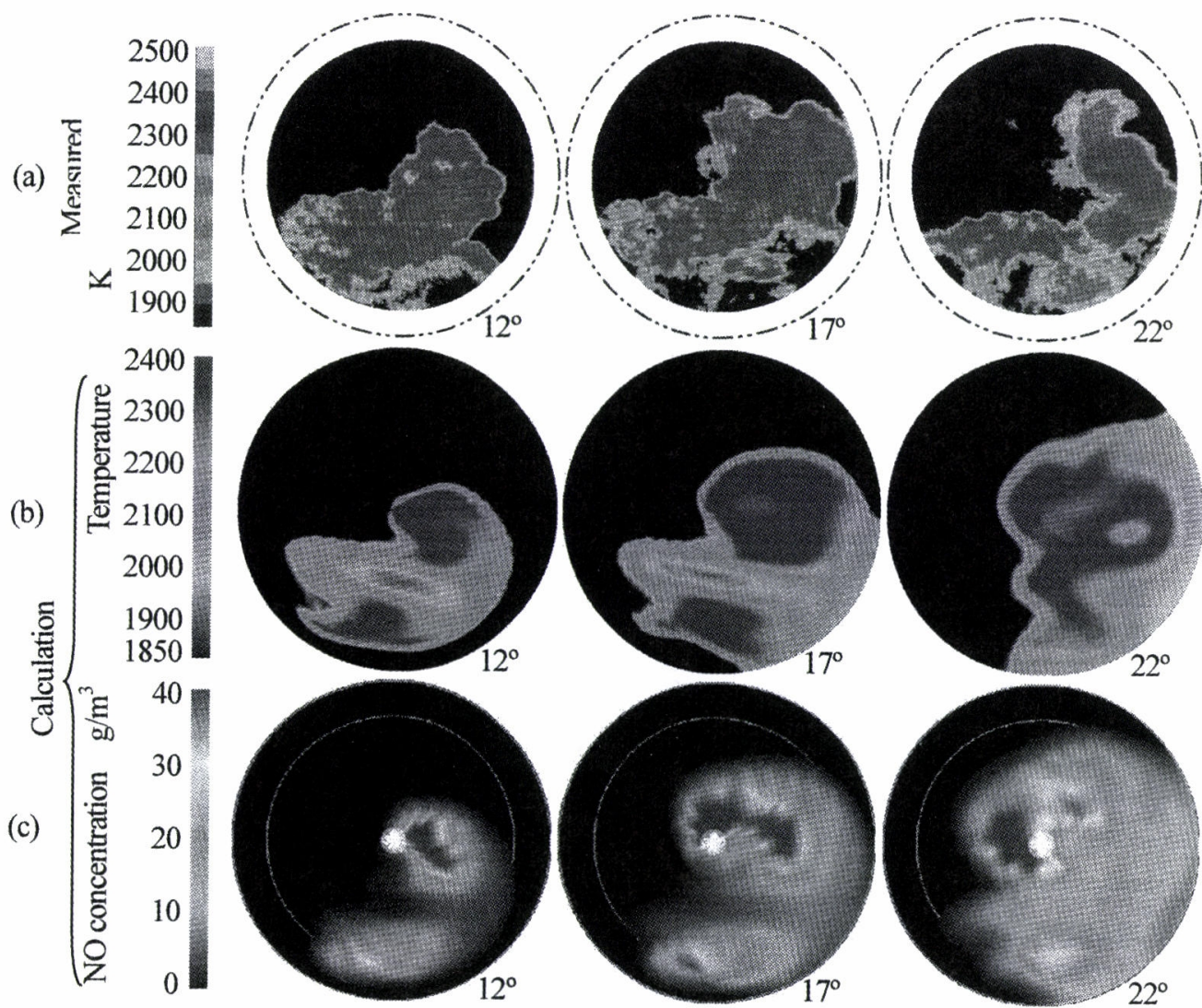

Crank angle

Fig.6 Comparison between experimental visual data and CFD results (without water injection) 
(b) and the calculated NO concentrations $\left(\mathrm{g} / \mathrm{m}^{3}\right)$ are demonstrated in (c). In this case, a volume of water equivalent to $50 \%$ of the fuel volume was injected at a pressure of $14 \mathrm{MPa}$.

As depicted in Fig.7 (a), almost all the areas of the flames, at each of the three time points, are successfully cooled down to the range of $2050-2200 \mathrm{~K}$. The predicted temperature distributions, Fig.7 (b), show that, in comparison with the fuel only case in Fig.6 (b), the red spots indicating temperatures hotter than $2300 \mathrm{~K}$ has become much smaller at each time point. Furthermore, Fig.7 (c) shows that the calculated NO concentrations following water injection are much smaller than those seen in Fig.6 (c). Moreover the spots where NO is actively formed, seen in Fig.6 (c), have all vanished at each time point. The calculated NOx values from the end of each cycle showed a $60 \%$ reduction in this case of a $50 \%$ vol. water injection.

Fig. 8 shows the flame temperatures and injected water distributions calculated by $\mathrm{StarCD}$ code under the same condition as Fig.7. As explained in 3.3, StarCD code is more convenient than KIVA code when used to detect the distribution of injected water. According to these figures, at 7 deg. ATDC, it is understood that the injected water spray is transported downstream by the air swirl and entrained into the flame. After that, the water spray extends into the flame, resulting in the successful cooling seen at $12-22 \mathrm{deg}$. ATDC. Considering the function of the air swirl demonstrated in this figure, it is supposed that extremely strong penetration is not necessary for the water spray.

\subsection{NOx measurement by CVCC test}

As it was impossible to measure NOx emissions from the visual test engine as explained in 2.3, and NOx values calculated by KIVA and StarCD codes were not perfectly reliable, CVCC, shown in Fig.5, was used to obtain the NOx reduction data from the application of the DWI system. In this experiment, the effects of the downward direction of the water spray, defined as the depression angle $\beta$ in Fig.9, on NOx reduction was specifically examined.

Fig.9 shows the results of this test. According to this figure,

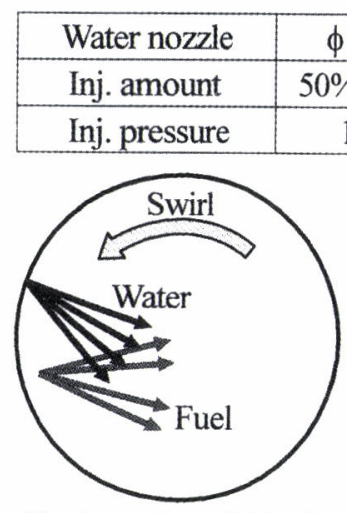

(Fuel nozzle: $\phi 0.23 \times 4$ )

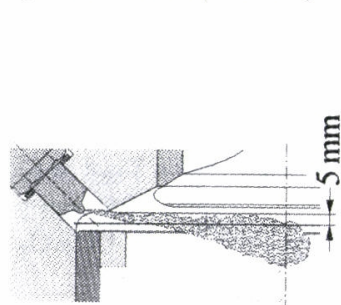

Calculated data are from a $5 \mathrm{~mm}$ cross-section

\section{Case: Type B" water injection}
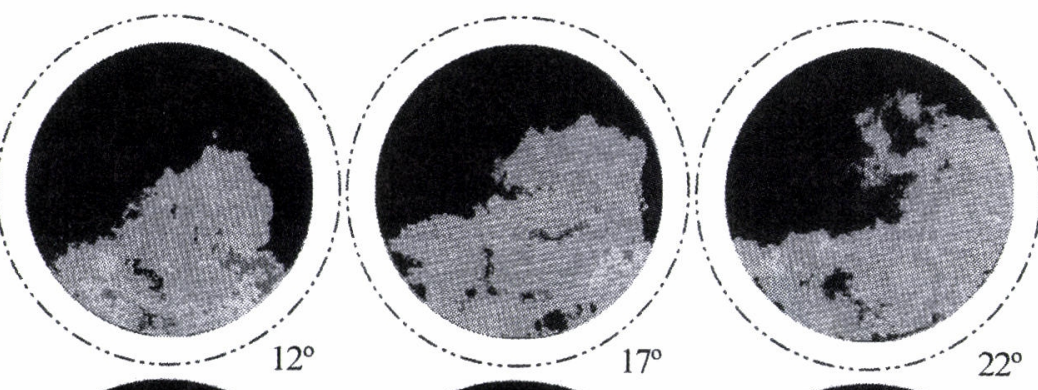

(a)

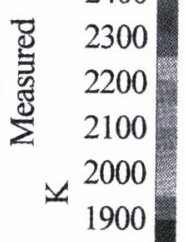
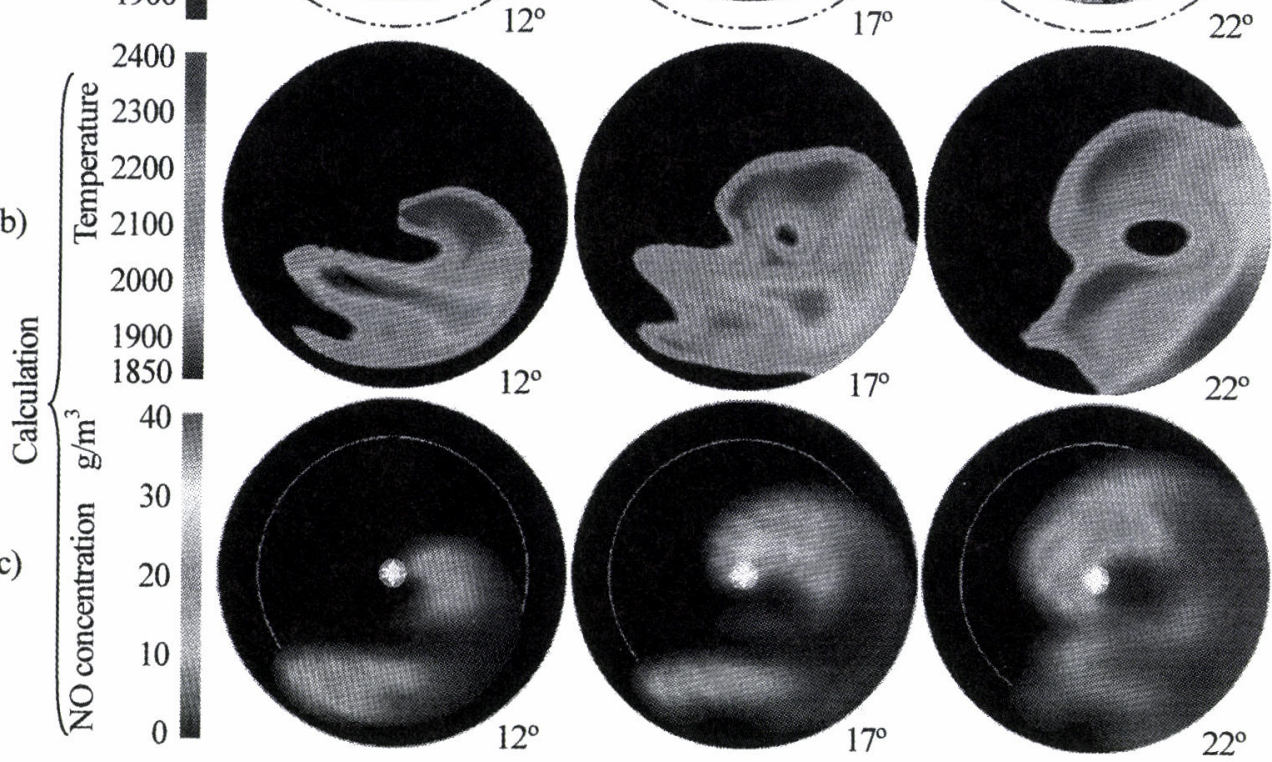

(b)
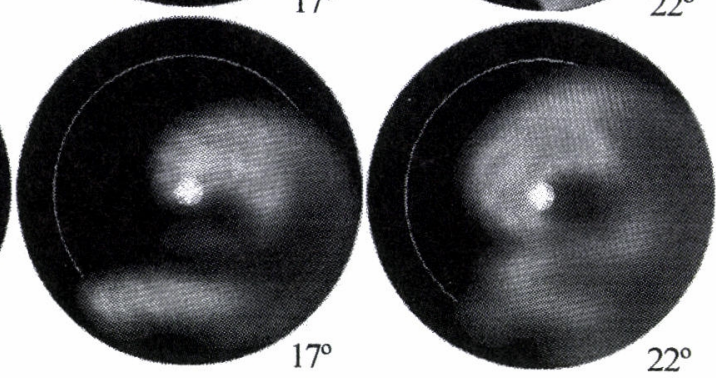

Crank angle

Fig.7 Comparison between experimental visual data and CFD results

(Water injection from upper stream of air swirl) 

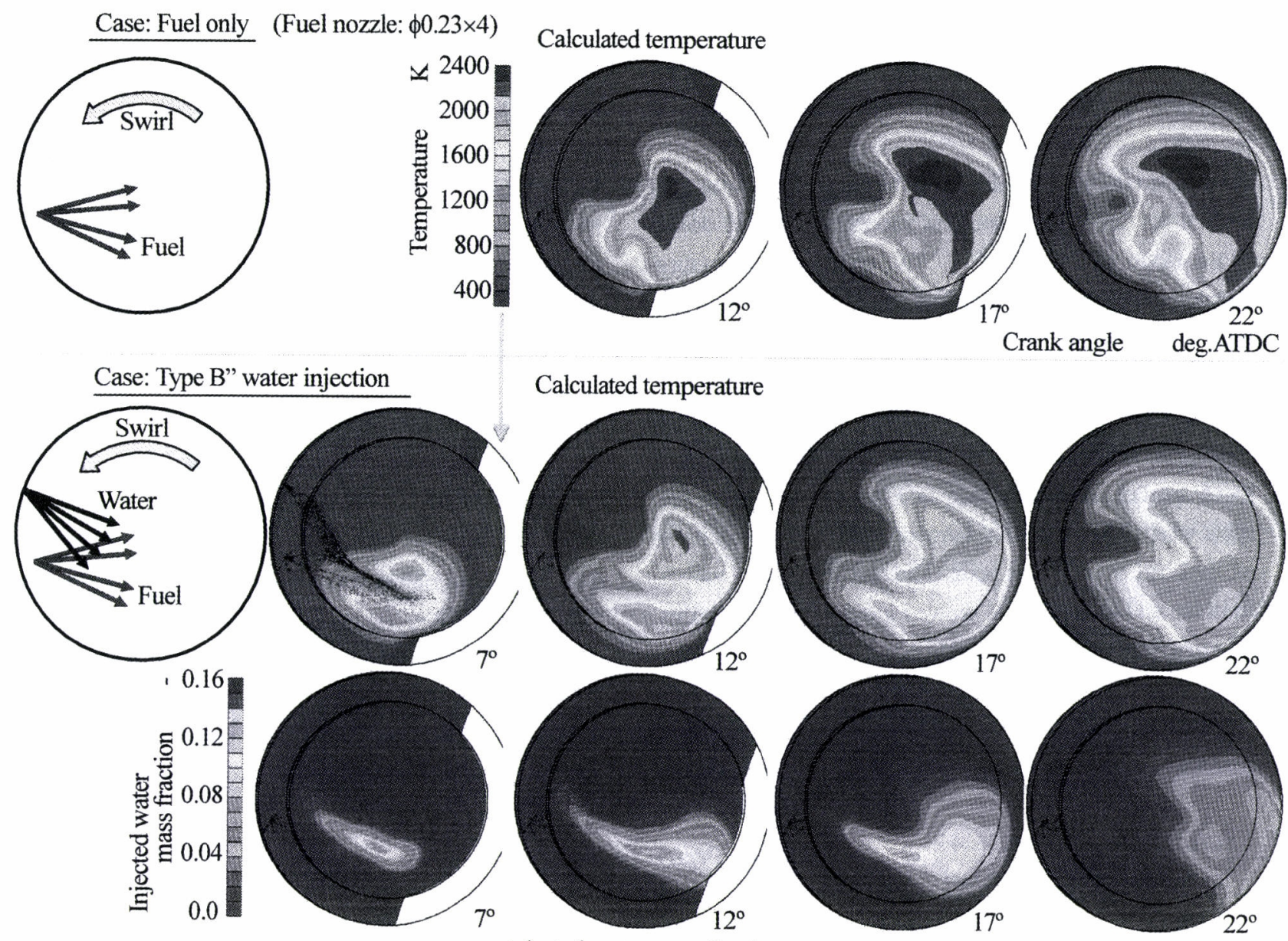

Calculated temperature
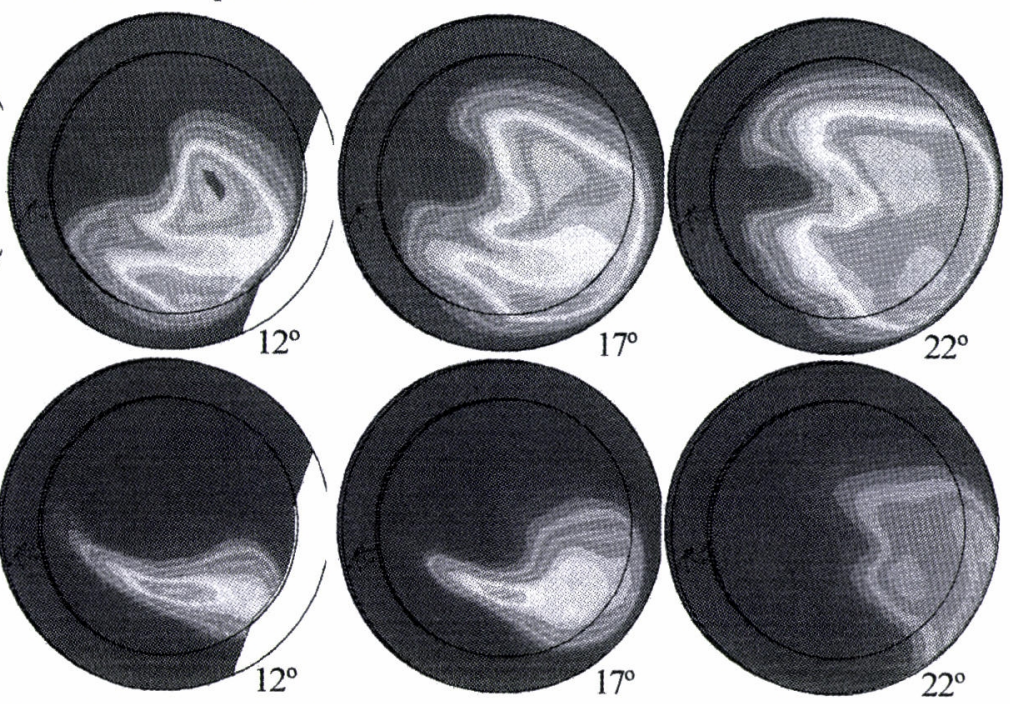

Injected water mass fraction

Crank angle deg.ATDC

Fig.8 Distribution of injected water by StarCD code (Oblique sections through spray axis, 50\% water injection)

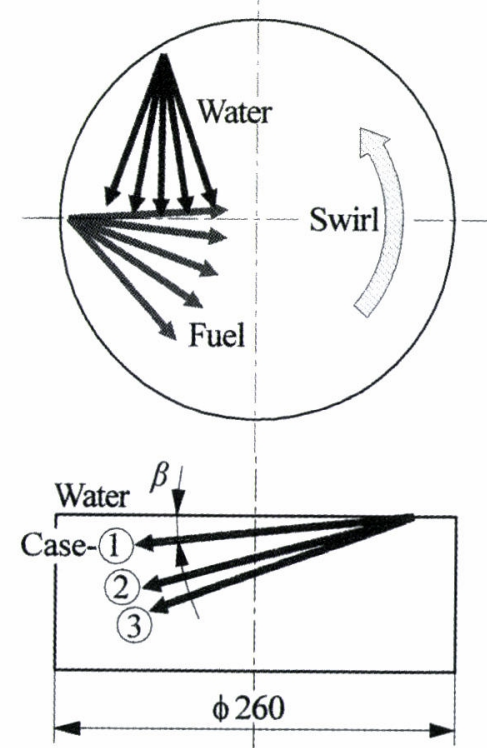

Depression angle $\beta$ is same for all five water injection holes in each case

\begin{tabular}{|l|c|c|}
\hline \multicolumn{3}{|c|}{ Injection condition in CVCC } \\
\hline & Fuel & Water \\
\hline Nozzle holes & $\phi 0.42 \mathrm{~mm} \times 5$ & $\phi 0.49 \mathrm{~mm} \times 5$ \\
\hline Injection pressure & $65 \mathrm{MPa}$ & $25 \mathrm{MPa}$ \\
\hline Injection duration & $12 \mathrm{~ms}$ & $12 \sim 20 \mathrm{~ms}$ \\
\hline Injected volume & $1.7 \mathrm{cc} / \mathrm{st}$ & $1.1 \sim 1.7 \mathrm{cc} / \mathrm{st}$ \\
\hline
\end{tabular}

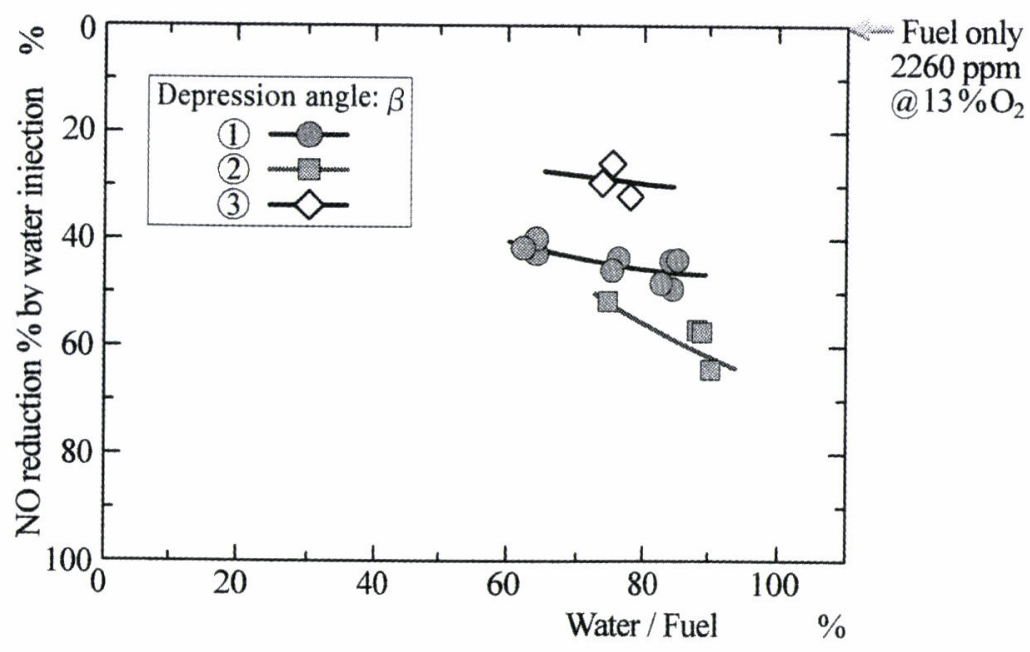

Fig.9 Experimental result using CVCC 
the NOx reduction rate strongly depends on the water injection angle $\beta$. A $\beta$ of $20 \mathrm{deg}$. showed the poorest results. This is considered to be the result of the water spray being injected too deeply and being distributed under the burning flame in the chamber, resulting in less overlapping with the flame. Similarly, in the case of 6 deg. $\beta$, the water spray would be located in the upper part in the chamber, above flame, again resulting in less overlapping.

It is considered that the two-dimensional analysis of the interaction between the flame and the water spray using the visual test engine, as explained in 4.1 , is not sufficient to determine the water injection nozzle specifications. Optimisation of the water spray distribution, aiming to cover the whole flame three-dimensionally, is essential for DWI to be applied successfully to relatively high combustion chambers like that of the long stroke engine.

\section{Conclusions}

In this paper, only a $65 \%$ reduction in NOx formation was confirmed in Fig. 9 by the CVCC test. However, the running test using a single-cylinder 2-stroke test engine in part 3 of this project has already been commenced by the engine builder member of this project. Using this engine, the target of this project, an $80 \%$ NOx reduction with a less than $3 \%$ increase of SFC, has almost been achieved at a low load
(25\% load) thanks to the fundamental research work and CFD methods explained in this paper.

This study was accomplished in collaboration with The Shipbuilding Research Association of Japan (renamed Japan Ship Technology Research Association from 2005) under the subsidy of The Nippon Foundation, for which the authors express their appreciation. The authors also thank all the members of this project (Class NK, Japan Internal Combustion Engine Federation, Japan NUS Co., Ltd., Kyushu University, Mitsubishi Heavy Industries, Ltd., Mitsui Engineering \& Shipbuilding Co., Ltd., NABCO (Nabtesco) Ltd. and Universal Shipbuilding Corporation) of this project.

Similarly, thanks are due to Dr. L. Goldsworthy, Australian Maritime College, for his co-operation (Star-CD calculation) in the project.

\section{References}

[1] Tajima, H. et al., Diagnosis of combustion with water injection using high-speed visualization and CFDs Proc. Thermo- and fluid dynamic processes in Diesel Engines: THIESEL 2004, pp.341-352, 2004 